\title{
Comparison of the Nutritional Status and Infant Feeding Practices Between Selected Rural and Urban Areas in Bangladesh
}

\author{
Abul Kashem Obidul Huq ${ }^{1, *}$, Nezamul Haque ${ }^{1,2}$, Farhana Akther1, Sonia Zebsyn ${ }^{3}$, \\ Jasmin Ara Farhana ${ }^{4}$, Sardar Mohammad Golam Moktadir ${ }^{1}$ \\ ${ }^{1}$ Department of Food Technology and Nutritional Science, Mawlana Bhashani Science and Technology University, Santosh, Tangail, \\ Bangladesh \\ ${ }^{2}$ Nutrition Intervention Bangladesh, Cox's Bazar Zone, Bangladesh \\ ${ }^{3}$ Department of Home Economics, National University, Gazipur, Bangladesh \\ ${ }^{4}$ Department of Human Nutrition and Dietetics, Patuakhali Science and Technology University, Patuakhali, Bangladesh
}

\section{Email address:}

obidulhuq@gmail.com (A. K. O. Huq)

${ }^{*}$ Corresponding author

\section{To cite this article:}

Abul Kashem Obidul Huq, Nezamul Haque, Farhana Akther, Sonia Zebsyn, Jasmin Ara Farhana, Sardar Mohammad Golam Moktadir. Comparison of the Nutritional Status and Infant Feeding Practices Between Selected Rural and Urban Areas in Bangladesh. Journal of Food and Nutrition Sciences. Vol. 5, No. 5, 2017, pp. 167-171. doi: 10.11648/j.jfns.20170505.11

Received: June 28, 2017; Accepted: July 7, 2017; Published: August 4, 2017

\begin{abstract}
The study was cross sectional design and carried out among 122 mother-infant pairs of the urban and rural areas in Tangail district, Bangladesh, aimed at the comparison of infant feeding practices and nutritional status of the rural and urban areas. There was a significant difference observed in their educational level (urban graduate $44.3 \%$ compared to rural graduate $2.4 \%$ ), total monthly income and expenditure on food and non-food items. The mean monthly income of urban and rural family were $34508.19 \pm 8227.67$ TK. and $6422.95 \pm 1756.23$ TK. respectively. Similarly monthly expenditure on foods of urban and rural family were $13090.16 \pm 2348.53 \mathrm{TK}$. and $4498.36 \pm 1394.76 \mathrm{TK}$. respectively. Colostrum feeding immediately after birth was higher in urban areas (75.4\%) compared to rural (47.5\%). Moreover, rural mother prefers to give honey and sugar water. In urban areas breast feeding initiated within 1 hour, but in rural areas it was given within 12 hours after birth. Urban mother provided powder milk (49.18\%) as first complementary foods, in contrast, rural mothers provided mainly cow's milk, hotchpotch made with vegetables and rice/cereal based products. Rural mother continued breast feeding practice for longer period of time than urban mothers. Majority of the urban mothers prefer egg, soup or fruits for their babies, while the rural people choices mainly the rice-potato, pulses or vegetables. The anthropometric indices shows that nutritional status of the urban infants was better than rural infants. The prevalence of moderate to severe underweight is higher in rural areas (59.01\%) when compared to urban areas (18.03\%). Again, moderate to severe stunted and wasted in rural areas found $39.34 \% \& 37.69 \%$ and in urban areas $21.31 \% \& 13.11 \%$ respectively.
\end{abstract}

Keywords: Infant, Feeding Practice, Complementary Foods, Colostrum, Nutritional Status

\section{Introduction}

Infant feeding practices are a cornerstone of care for childhood growth, development, health, and ultimately the survival of infants and young children [1, 2]. World-wide a lot of under five children are stunted as a consequence of poor feeding and repeated infections. Even in resource poor settings, improved feeding practices can lead to improved intakes of energy and nutrients, leading to better nutritional status. Over the past decades, the evidence of biological requirements for appropriate nutrition, recommended feeding practices and factors impeding appropriate feeding has grown steadily. Moreover, much has been learned about interventions that are effective in promoting improved 
feeding. For example, recent studies in Bangladesh, Brazil and Mexico have demonstrated the impact of counseling, in communities and health services, to improve feeding practices, food intake and growth [3].

Breastfeeding remains the simplest, healthiest and least expensive feeding method that fulfils the infants' needs [4]. The health benefits of breastfeeding to both mother and infant have been well documented. It has been observed that infants aged $0-5$ months who are not breast fed have sevenfold and five-fold increased risks of death from diarrhea and pneumonia, respectively, compared with infants who are exclusively breastfed [5].

Complementary feeding is another very important component of infant feeding. After six months, mother's milk is not sufficient for the growing child and complementary feeding should be started, timely and in adequate amounts. Frequency and amount of top feeds given during the weaning period to children are important variables in the pathogenesis of malnutrition. Inappropriate feeding practices during this period, is the major cause of malnutrition [6]. The World Health Organization (WHO) recommends exclusive breastfeeding for the first 6 month of life and continuation of breastfeeding for two years [7].

Usually in a culture where infant feeding practice is dominated by breast-feeding, delayed supplementation is the rule and infant malnutrition is very common. Previous data showed a dreadful picture of the infant and children in Bangladesh who are suffering from various degrees of malnutrition. At that time, outbreaks of diarrheal infection, nutritionalblindness, morbidity and mortality increased [8]. Feeding practices have long been associated with nutritional knowledge as well as their educational level. Child health situation is not satisfactory level and a large number of children suffer from various degree of malnutrition. The prevalence of underweight, stunted and wasted of under five children for the last decade were 46,43 and $17 \%$ respectively [9]

Therefore, the study was design for the situation analysis of complementary feeding practices in Bangladesh and the nutritional status of the selected areas were the main objective to compare its nature and extent in rural versus urban basis.

\section{Methods and Materials}

\subsection{Type of Study Design}

The study was a descriptive type of cross sectional study among the selected infant and mother pairs in Tangail region. The areas selected for this study are different villages of Jolchotro union at Modhupur and Tangail town under Tangail district, Bangladesh. The study was conducted from January 2013 to September 2013. The time preceding and following this period was utilized for questionnaire development, data collection, data entry, and data analysis. Data Collection Period was 15th February to $15^{\text {th }}$ April 2013.

\subsection{Sampling Technique and Sample Size}

Simple random sampling was followed. At first, a pilot survey was done among the different villages of Jolchotro union at Modhupur (rural) and Tangail town (urban) under Tangail district, Bangladesh and collected the information about socio-economic conditions such as income, expenditure, profession, place of living areas, conditions of living areas, anthropometrical information, personal hygiene, socio-cultural behavior, food intake pattern etc. The researcher visited to the rural and urban area of infant bearing households. After fulfilling the selection criteria for inclusion in the study, the sample is selected randomly. 61 rural and 61 urban infant bearing mothers were interviewed.

No. of Sample for Each Area

A number of 61 individual infant-mother pair was randomly selected from the each area and the following sample size calculation formula were used.

$1.96^{2} \mathrm{XP}$

$$
\text { Sample Size }(\mathrm{n})=\frac{1.96^{2} \times P}{(1-P) \times €^{2}}
$$

(1-P) $X €^{2}$

or, $\mathrm{n}=61$ for each area

Total Sample Size $(\mathrm{n})=\mathrm{n}$ Xk

or, $\mathrm{n}=122$

Here, $\mathrm{n}=$ group sample size; and $\mathrm{n}=$ Total sample size

$1.96^{2}=$ the value of $95 \%$ confidence interval

$\mathrm{P}=$ Prevalence of malnourished individual mother-child pair $=0.5$ (Assumed normally)

$(1-\mathrm{P})=$ Prevalence of well nourished

$€^{2}=$ Required Precision

$\mathrm{k}=$ Design factor $=2$

\subsection{Collection of Anthropometric Information}

The anthropometrical data such as weight and height of the babies were taking individually; Weight was recorded in kilograms and height in $\mathrm{cm}$. The babies who were less cooperative were weighted together with their mothers. The weight of the baby was obtained by subtracting the weight of the mother.

\subsection{Collection of Dietary Information}

In this section of the respondents are asked about the food intake pattern about the baby. When they started complementary food, are they continued breast feeding. Here mothers were also questioned about complementary infant feeding practices, what they gave as supplementary food to their infant.

\subsection{Data Analysis}

All the statistical analysis and all other data processing were done by using SPSS 16.0 windows program. Descriptive statistics was mainly used. Data were analyzed in terms of frequency distribution, crosstabs, percentage means and standard deviation. Statistical test, and correlation coefficient were used to find out the association between 
selected various form socio-economic status, Anthropometric status income, expenditure, working environment, load, nutritional status, dietary and disease pattern and cultural superstitions. The raw anthropometric data of SPSS 16.0 were transferred to WHO Anthro to obtain derived indices of anthropometric measurements, such as weight for age, height for age and weight for height Z-score, percentiles and median of children and BMI for adults. The indices obtained from 'anthro' version 1.01 were then transferred again to the SPSS 16.0 windows for further analysis on the basis of different socio-economic and cultural aspects. For tabular, charts and graphical representation Microsoft word and Microsoft excel were used.

\section{Results and Discussion}

Table1 shows the educational level of the respondents by different areas. About fifty percent (49.8\%) of the rural respondents were illiterate, $36.6 \%$ completed primary level, and $6.9 \%$ accomplished SSC level. Among the urban respondents $44.3 \%$ were completed graduate and $37.7 \%$ passed HSC level. Thus, it can be concluded that urban respondents were highly educated compared to rural respondents.

Table 2 shows the comparison between monthly income and food expenditure of the respondent's family. It was observed that mean monthly income of urban population is $34508.19 \pm 8227.67 \mathrm{TK}$. of which mean monthly food expenditure is $13090.16 \pm 2348.53 \mathrm{TK}$. On the other hand, in rural society, mean monthly income is $6422.95 \pm 1756.23$ TK. of which mean monthly food expenditure is $4498.36 \pm 1394.76$ TK. Another study showed the average monthly income of the rural Tangail area were between $4000-9000$ Tk. [10].

Table 1. Education level of the respondent.

\begin{tabular}{lll}
\hline Education level & Urban arean (\%) & Rural arean (\%) \\
\hline Illiterate & $0(0.0)$ & $30(49.8)$ \\
Primary & $0(0.0)$ & $22(36.6)$ \\
SSC & $11(18.0)$ & $4(6.9)$ \\
HSC & $23(37.7)$ & $3(4.3)$ \\
Graduate & $27(44.3)$ & $2(2.4)$ \\
Total & $61(100)$ & $61(100)$ \\
\hline
\end{tabular}

Table 2. Comparison between monthly income and food expenditure.

\begin{tabular}{lll}
\hline Locations & $\begin{array}{l}\text { Monthly income (TK) } \\
\text { Mean } \pm \boldsymbol{S D}\end{array}$ & $\begin{array}{l}\text { Food expenditure (TK) } \\
\boldsymbol{M e a n} \pm \boldsymbol{S D}\end{array}$ \\
\hline Urban area & $34508.19 \pm 8227.67$ & $13090.16 \pm 2348.53$ \\
Rural area & $6422.95 \pm 1756.23$ & $4498.36 \pm 1394.76$ \\
\hline
\end{tabular}

Table 3 shows that in urban area majority (73.8\%) respondent initiated breast feeding within one hour, while in rural area highest percentage $(83.6 \%)$ initiated it within 12 hours. Moreover, Table 4 shows the majority of babies in both urban and rural area first introduce colostrum by $75.4 \%$ and $47.6 \%$ respectively. It also observed that $18.0 \%$ of urban mother first give formula milk, while in rural area preference of giving honey and sugar water were $21.3 \%$ and $18.0 \%$ respectively. Similar pattern of first introducing items such as honey, sugar water or formula milk also offered by urban working lactating mother in another study [11].

Table 3. Comparison among starting times of breast feeding.

\begin{tabular}{lll}
\hline $\begin{array}{l}\text { Breast feeding } \\
\text { Initiation time }\end{array}$ & Urban arean (\%) & Rural arean (\%) \\
\hline$<1$ hour & $45(73.8)$ & $7(11.5)$ \\
$<12$ hours & $14(22.9)$ & $51(83.6)$ \\
$<24$ hours & $2(3.3)$ & $3(4.9)$ \\
$<48$ hours & $0(0.0)$ & $0(0.0)$ \\
Total & $61(100)$ & $61(100)$ \\
\hline
\end{tabular}

Table 4. Comparison of foods first introducing to the baby after birth.

\begin{tabular}{lll}
\hline Food items & Urban arean (\%) & Rural arean (\%) \\
\hline Colostrum & $46(75.4)$ & $29(47.6)$ \\
Honey & $4(6.6)$ & $13(21.3)$ \\
Sugar water & $0(0)$ & $11(18.0)$ \\
water & $0(0)$ & $5(8.2)$ \\
Formula milk & $11(18.0)$ & $3(5.2)$ \\
Total & $61(100)$ & $61(100)$ \\
\hline
\end{tabular}

Table 5 shows the distribution of the all respondents when introduce the complementary foods their babies and it is highlighted that $44.3 \%$ and $36.1 \%$ urban and rural mothers respectively started complementary feeding at 3 months of baby. Early initiation of complementary feeding in both rural and urban areas of Bangladesh is a major concern as several studies showed that majorities of the mothers initiated weaned food before six months $[8,11]$. The recommended right age of complementary feeding is six months, which is better practices in West Bengal (55.7\%) [12]. In Bangladesh, another study showed exclusive breast feeding at 6 months was $94 \%$ in the normal birth weight infants and $92 \%$ in the low birth weight infant [13] Again, Table 6 indicates more than one third (41.0\%) of the rural infants provide cow's milk as first complementary food on the other hand, about half (49.2\%) of the urban infants introduce powder milk as first complementary food. Although milk is good for babies, but first complementary foods should be bland, smooth and tasty. Usually, the common practice in Bangladesh is a sweet products made from rice, sugar and milk together (Locally known as Payesh/Kheer) is introduce firstly at a certain occasion [11].

Table 7 shows majorities of the respondents in each group were frequently complement 5-8 times per day mainly and this frequency depend on the infant's age, mother's available time and income of the family. A similar complementary feeding frequency (5-6 times) was observed in another study of Bangladesh. In India, a study showed very similar, $48.6 \%$ urban mothers feed 5-6 times per day $[14,15]$.

Figure 1 indicates $14.75 \%$ urban and $19.71 \%$ rural mothers continue exclusive breast feeding until 5 to 6 months. On the other hand, 60.66 and $68.85 \%$ mother continue exclusive breast feeding for 3 to 4 month in urban and rural area respectively. 
Table 5. Comparison of the time of initiation complementary foods to their babies.

\begin{tabular}{lll}
\hline Stages of complementary foods introduce & Urbann(\%) & Ruraln(\%) \\
\hline 1 month & $3(4.9)$ & $0(0.0)$ \\
2 months & $12(19.7)$ & $6(9.8)$ \\
3 months & $27(44.3)$ & $22(36.1)$ \\
4 months & $10(16.4)$ & $20(32.7)$ \\
5 months & $7(11.5)$ & $8(13.1)$ \\
6 months & $2(3.3)$ & $1(6.6)$ \\
$>6$ months & $0(0.0)$ & $61(100)$ \\
Total & $61(100)$ & $61.6)$ \\
\hline
\end{tabular}

Table 6. First foods introduced as a complementary foods.

\begin{tabular}{lll}
\hline First food as a complementary & Urban arean (\%) & Rural arean (\%) \\
\hline Milk/powder milk & $30(49.2)$ & $0(0)$ \\
Cow's milk & $8(13.1)$ & $25(41.0)$ \\
Rice mashed & $3(4.9)$ & $15(24.6)$ \\
Semolina (Suji) & $10(16.4)$ & $14(22.9)$ \\
Vegetables & $6(9.8)$ & $4(6.6)$ \\
Fruit juice & $4(6.6)$ & $3(4.9)$ \\
Total & $61(100.0)$ & $61(100.0)$ \\
\hline
\end{tabular}

Table 7. Frequency of complementary foods given by the different areas.

\begin{tabular}{lll}
\hline Frequency per day & Urbann(\%) & Ruraln(\%) \\
\hline$<4$ & $2(3.3)$ & $7(11.5)$ \\
$5-6$ & $38(62.3)$ & $42(68.9)$ \\
$7-8$ & $12(19.7)$ & $6(9.8)$ \\
$>8$ & $9(14.8)$ & $6(9.8)$ \\
Total & $61(100$ & $61(100)$ \\
\hline
\end{tabular}

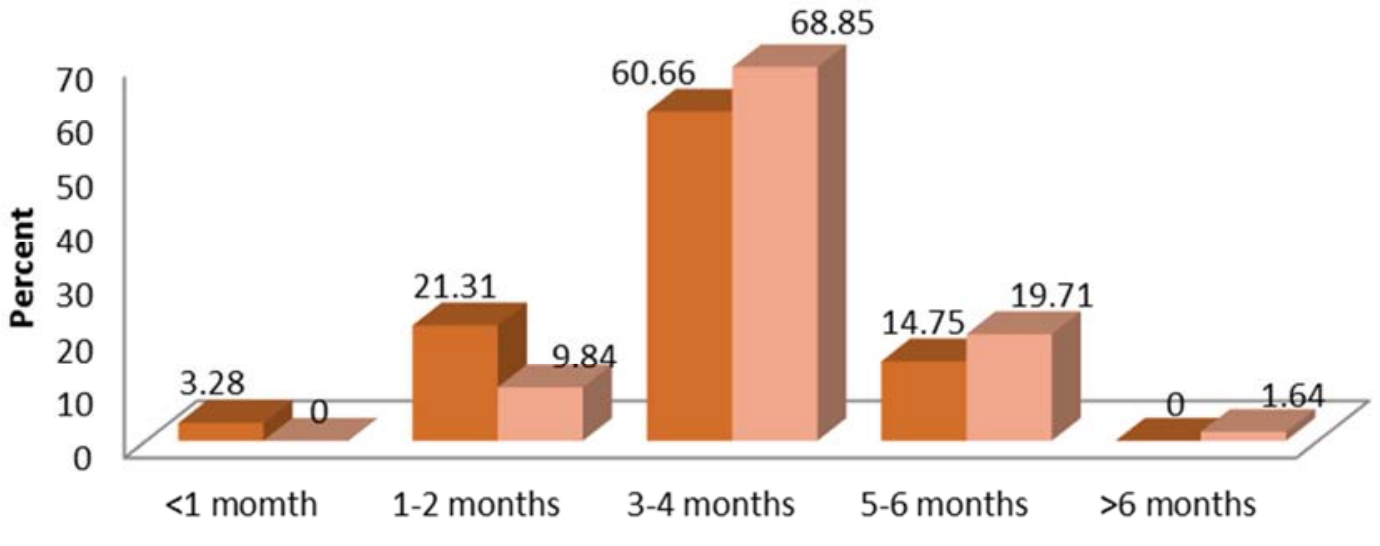

Comparison the duration of exclusive breast-feeding

\section{- Urban Rural}

Figure 1. Comparison among duration of exclusive breast-feeding.

Figure 2 indicates that according to Z-score urban infant's nutritional status were better than rural infants. Moderate to severe underweight in rural area $(45.90+13.11=59.01 \%)$, and in urban area $(16.39+1.64=18.03 \%)$ indicated a lowering trend of underweight from rural to urban areas. Moderate to severe stunted in rural areas, $(26.23+13.11=39.34 \%)$, and in urban areas $(18.03+3.28=21.31 \%)$ indicated a lowering trend of stunted like underweight from rural to urban areas. Moderate to severe wasted in rural areas $(34.43+3.28=37.69 \%)$, and in urban areas $(13.11+0.00=13.11 \%)$ indicated a lowering trend of wasted like underweight and stunted from rural to urban areas. Similar results were observed in Mpigi district, Uganda (Stunting 32\%, wasting 3\% and underweight 10\%) [16].

\section{Conclusions}

A scientific feeding practice is crucial for infant's growth and development. Complementary feeding is an essential component of infant feeding practices. Important finding of this study is, more scientific feeding practice found in urban respondent than rural this is mainly due to 
education and income factors. The nutritional status of the selected infants were found to be varied with varying degrees, but improved nutritional condition found in urban infants than rural. However, regardless of the financial and educational qualifications of the respondent mothers, it was found that the knowledge, attitude and practices complementary feeding was at satisfactory level. Emphasis should be given to infant feeding practices education sessions for both urban and rural mothers to prevent higher prevalence of malnutrition.

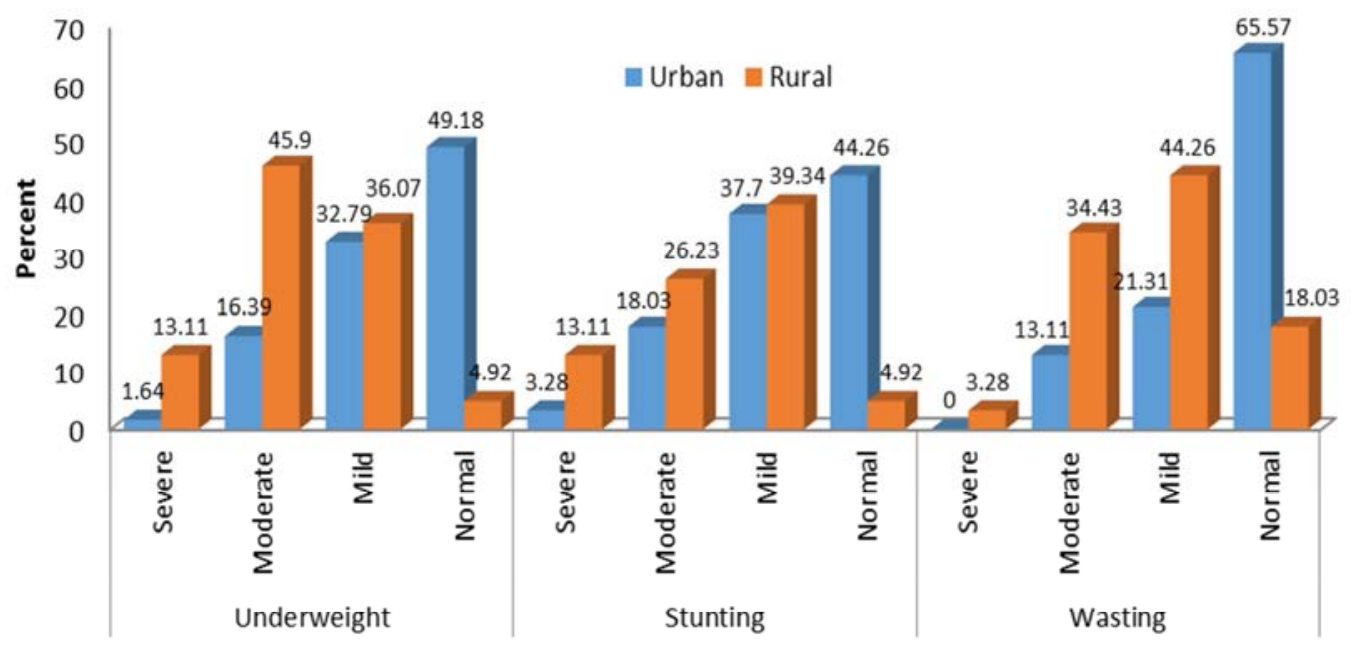

Nutritional status

Figure 2. Comparison of the nutritional status of the urban and rural infant.

\section{References}

[1] Frongillo, E. A., Alam D. S, Ariffen S. E, Persson L. A and Rasmussen K. M. "Appropriate infant feeding practices result in better growth of infants and young children in rural Bangladesh". Am J ClinNutr. 2008; 87: 1852-9.

[2] Ahmed, T., Black, R. E, Cousens, S. Dewey, K. and Giugliani $\mathrm{E}$, "Interventions for maternal and child under nutrition and survival”. Lancet. 2008; 371: 417-40.

[3] Global Strategy for Infant and Young Child Feeding, WHOUNICEF, 2003. www.who.int/nutrition/topics/global_strategy.

[4] Kramer, M. S and Kakuma R. "The optimal duration of Exclusive breastfeeding. A systematic review". WHO, Geneva, Switzerland. 2002; WHO/NHO/01.08.

[5] Arifeen, S., Black R. E, Antelman G, Baqui A, Caulfield L and Becker S. "Exclusive breastfeeding reduces acute respiratory infection and diarrhoea deaths among infants in Dhaka slums". Pediatrics. 2001; 108: E 67.

[6] World Health Organization."Complementary feeding of young children in developing countries: a review of current scientific knowledge". Geneva: World Health Organization; 1998. p. 237. (WHO/NUT/98.1).

[7] World Health Organization. "The optimal duration of exclusive breastfeeding. Report of an Expert Consultation". Geneva, Switzerland: World Health Organization, 2002.

[8] Bhuyan, M. A. H, Islam K and Ali M. Y. "Child Caring and Complementary Feeding Practices among Selected Households in Dhaka City". The ORION Medical Journal. 2010, 33 (1):718-721.
[9] UNICEF. "Basic Indicators, Health and Nutrition indicators, UNICEF-Bangladesh-statistics". 2012.

[10] Islam, M. S., Jothi, J. S., Islam, M. and Huq, A. K. O. "Nutritional Status of Rural and Urban Under-Five Children in Tangail District, Bangladesh". International Journal of Innovation and Applied Studies, 2014; 8 (2): 841-848.

[11] Tanni, C., Roy, P., Obidul, H and Shaon, K. A. "Infant and Young Child Feeding Practices among the selected Urban Working Lactating Mother, Bangladesh". Research \& Reviews: Journal of Medicine, 2014; 4 (3): 1-8.

[12] Sinhababu, A., Mukhopadhyay, D. K. and Panja, T. K. "Infant and young cild feeding practices in Bankura district, West Bengal, India” J Health Popul. Nutr. 2010; 28 (3): 294-99.

[13] Haider, R. and Saha, K. K. "Breastfeeding and infant growth outcomes in the context of intensive peer counselling support in two communities in Bangladesh." International Breastfeeding Journal. 2016; 11(1):18.

[14] Ullah, M. I. N. Islam, M. N. and Islam, M. A. "Feeding practices in infants attending children outpatients department of IPGMR, Dhaka, Bangladesh”. Bangladesh Pediatrics. 1983; 7 (3-4): 80-84.

[15] Khan, A. M., Kayina, P., Agarwal P., Gupta, A. and Kannan A. T. "A study on infant and young children feeding practices among mothers attending an urban health center in East Delhi”. Indian J Public Health. 2012; 56 (4): 301-304.

[16] Tumwesigye, N. M., Tushemerirwe, F. B., Kajjura, R., Nabunya, V., Naitala, R. A. and Namanda, C. "Nutritional status, feeding practices and state of other related indicators at onset of a multi-model community nutrition intervention program in Mpigi District, Uganda." African Health Sciences, 2016; 16(4), 892-903. 